\title{
O BEM-VIVER COMO ALTERNATIVA AOS MODELOS DESENVOLVIMENTISTAS
}

\section{BUEN VIVIR AS AN ALTERNATIVE TO DEVELOPMENTAL MODELS}

\author{
Adriano Ermerson Oliveira Vasconcelos ${ }^{16}$
}

\begin{abstract}
It seeks to analyze alternatives to the development model that has been imposed by globalization to all countries. The concept is part of the political agenda of the governments of the most varied nations. The model is eurocentrist and neo-colonialist, since the European countries, or "the center", are at the apex of a supposed human social evolution and that the others, still in the process of "development", must submit to "Europeanize". Alternatively, it starts from recent Ecuadorian and Bolivian constitutional experiences, which represent a paradigmatic transition from anthropocentrism to biocentrism, through the recognition of Nature (Pachamama) as a subject of rights and establishment of a harmonious relationship with nature and all its beings, human or not. It is intended to present a viable alternative applicable to the disastrous tax model.
\end{abstract}

\section{RESUMO}

Busca analisar alternativas ao modelo de desenvolvimento que vem sendo imposto pela globalização a todos os países. O conceito faz parte da agenda política dos governos das mais variadas Nações. O modelo é eurocentrista e neocolonialista, na medida em que parte de que os países Europeus, ou "do centro", se encontram no ápice de uma suposta evolução social humana e que os demais, ainda em vias de "desenvolvimento", devem se submeter para "europeizarem-se". Como alternativa, parte-se das recentes experiências constitucionais Equatoriana e Boliviana, que representam transição paradigmática do antropocentrismo para o biocentrismo, através do reconhecimento da Natureza (Pachamama) como sujeito de direitos e do estabelecimento de uma relação harmoniosa com a Natureza e todos os seus seres, humanos ou não. Pretende-se apresentar uma alternativa viável e aplicável ao desastroso modelo imposto.

\section{KEYWORDS}

Development Alternatives; Well-Living; Anthropocentrism; Biocentrism

\section{PALAVRAS-CHAVE}

Alternativas ao Desenvolvimento; Bem-Viver; Antropocentrismo; Biocentrismo.

\section{Introdução}

O processo de globalização que se encontra avançado e já consolidado, é fruto de um sistema que teve início com a colonização do Continente Americano e com o

\footnotetext{
${ }^{16}$ Mestre em Direito Agrário, Universidade Federal de Goiás: adriano.vasconcelos.adv@gmail.com
} 
estabelecimento do capitalismo colonial/moderno, de cunho eurocêntrico, como padrão estabelecido de poder mundial (QUIJANO, 2000, p. 201).

\begin{abstract}
Uno de los ejes fundamentales de ese patrón de poder es la clasificacion social de la población mundial sobre la idea de raza, una construccion mental que expresa la experiencia basica de la dominación colonial y que desde entonces permea las dimensiones más importantes del poder mundial. Dicho eje tiene, pues, origen y carácter colonial, pero ha probado ser más duradero y estable que el colonialismo en cuya matriz fue estabelecido. Implica, en consecuencia un elemento de colonialidad en él patrón de poder hoy establecido (QUIJANO, 2000, p. 201).
\end{abstract}

Assim, com a colonização do, então recém-descoberto, Continente Americano, as duas potências ultramarinas ibéricas: Espanha e Portugal, cada uma em seus respectivos territórios conquistados, trataram de impor relações entre sua própria gente, entre os habitantes originários da América e, mais tarde, entre os contingentes humanos trazidos da África e escravizados.

Paulatinamente, os papéis a desempenhar nas sociedades coloniais americanas foram se encaixando, de maneira arbitrária, mas com certa previsibilidade, de acordo com a "relevância" que era dada a cada indivíduo segundo sua posição social, étnica, influência e grau de importância para os interesses das Coroas.

Dessa forma, "raça e identidade racial foram estabelecidas como instrumentos de classificação social básica da população". O critério de raça acabou por se constituir como “primeiro critério fundamental para a distribuição da população mundial nos níveis, lugares, e papéis na estrutura de poder da nova sociedade. Em outras palavras, no modo básico de classificação social universal da população mundial” (QUIJANO, 2000, p. 202).

Do ponto de vista eurocêntrico, formas de trabalho baseadas na escravidão e servidão (no imaginário unilinear da perspectiva cronológica de uma suposta evolução da sociedade europeia frente aos demais povos do mundo), fazem parte do passado. Ou seja, são próprias de períodos anteriores ao estabelecimento do capital e, portanto, pré-capitalistas. Entretanto, como pontua Aníbal Quijano:

En América la esclavitud fue deliberadamente establecida y organizada como mercancia para producir mercancias para el mercado mundial y, de ese modo, para servir a los propositos y necesidades del capitalismo. Así mismo, la servidumbre impuesta sobre los indios, inclusive la redefinicion de las instituciones de la reciprocidad, para servir los mismos fines, i.e, para producir mercancías para el 
mercado mundial. Y en fin, la produccion mercantil independiente fue establecida y expandida para los mismos propositos (QUIJANO, 2000, p. 219).

Portanto, formas ditas "pré-capitalistas", como servidão e escravidão, foram largamente utilizadas na América, mesmo após a independência política dos países latinoamericanos, ao lado de outros instrumentos de cunho colonial, como base para o sistema de acumulação de capital a nível internacional.

A medida em que as estruturas de poder se fortaleciam, todos os traços da existência cultural dos povos colonizados passaram a ser apagados, ressignificados segundo a cosmovisão do colonizador.

Neste sentido, assinala Quijano (2000) que:

Ese resultado de la história del poder colonial tuvo dos implicaciones decisivas. La primera es óbvia: todos aquellos pueblos fueron despojados de sus própias identidades históricas. La segunda es, quizas, menos óbvia, pero no es menos decisiva: sua nueva identidad racial, colonial y negativa, implicaba el despojo de su lugar en la historia de la produccion cultural de la humanidad (QUIJANO, 2000, p. 221).

Daí em diante, não apenas passaram a ser considerados como povos ou raças inferiores, e, portanto, fadadas à produção de uma cultura de "segunda classe", desta imposição e ressignificação colonial se derivaram novas realocações em que tais povos passaram a representar o "passado", espelhando o "primitivo", enquanto que a Europa passou a ser identificada com o "moderno" (QUIJANO, 2000, p. 221).

No decorrer do Século XVIII, a ideia de progresso associado a mitos fundacionais da civilização europeia em oposição a um alegado estado de natureza e, portanto, selvagem dos povos colonizados foi ganhando força, servindo de base para teorias que sustentavam a perspectiva local europeia como o ápice da evolução social humana e que, diante disso, os demais povos estavam em vias de "desenvolvimento". Assim todos os povos não europeus foram classificados como em um processo de "desenvolvimento" que ia do "primitivo ao civilizado". "En otras palabras, desde lo no-europeo/pre-europeo a algo que en el tiempo se europeizará o 'modernizará'”' (QUIJANO, 2000, p. 225).

Os modelos de desenvolvimento econômico que se encontram em uso pela maioria dos países do mundo estão inseridos na lógica neocolonial global, reproduzindo sua 
lógica colonial através dos arquétipos de "desenvolvimento" e "subdesenvolvimento" por meio dos quais classificam os países e suas populações segundo critérios hierárquicos.

\section{O racismo e o sexismo como elementos da modernidade}

Partindo do sistema de pertença hierarquizada, assinalado por Boaventura de Sousa Santos (1999), na modernidade capitalista tanto o racismo quanto o sexismo são modalidades de hierarquização e abarcam elementos tanto da desigualdade quanto da exclusão. Assim:

No caso do racismo, o princípio de exclusão assenta na hierarquia das raças e a integração desigual ocorre, primeiro, através da exploração colonial, e depois, através da imigração. No caso do sexismo, o princípio da exclusão assenta na distinção entre o espaço público e o espaço privado e o princípio da integração desigual, no papel da mulher na reprodução da força do trabalho no seio da família e, mais tarde, tal como o racismo, pela integração em formas desvalorizadas de força de trabalho. Por um lado, a etnicização/racialização da força de trabalho. Por outro, a sexização da força de trabalho" (SANTOS, 1999, p. 3).

Dessa forma, o sistema de desigualdade se encontra assentado no ideário de igualdade, o que explica a razão pela qual o contrato de trabalho se dá entre "partes livres e iguais". Já o sistema de exclusão se assenta no essencialismo da diferença, seja ela a imposição de um padrão de normalidade ou o determinismo biológico da desigualdade racial ou social (SANTOS, 1999, p. 4).

Portanto, tanto a desigualdade quanto a exclusão comportam variadas gradações que se apresentam complexas e mais ou menos difíceis de se identificar, a depender da estrutura social em que estejam inseridas. Assim, "quer a desigualdade, quer a exclusão permitem diferentes graus. O grau extremo de exclusão é o extermínio: o extermínio dos judeus e dos ciganos no nazismo, a limpeza étnica dos nossos dias. O grau extremo da desigualdade é a escravatura" (SANTOS, 1999, p. 4). Neste contexto, explica Boaventura:

A desigualdade entre o capital e o trabalho, a exclusão do interdito, o racismo e o sexismo foram construídos socialmente enquanto princípios de hierarquização social no âmbito das sociedades nacionais metropolitanas (...) Mas desde o início da expansão capitalista estes princípios de hierarquização e discriminação têm um outro espaço-tempo: o sistema mundial onde também desde sempre se misturaram 
os princípios da desigualdade e de exclusão. Por um lado, a desigualdade pelo trabalho escravo; por outro, a exclusão pelo genocídio dos países indígenas" (SANTOS, 1999, p. 4).

Dessa forma, tanto a desigualdade quanto as exclusões sociais foram processos retroalimentados pelo avanço do sistema capitalista ao longo do tempo e ao redor do Globo. Assim, a modernidade (e com ela seu eixo desenvolvimentista), é ela própria geradora de desigualdade e exclusão, cumprindo papel exatamente oposto ao pregado por seus defensores.

Segundo o mesmo autor, o conceito de desenvolvimento capitalista se denota por meio do ideário de universalismo que pode se apresentar pela via anti-diferencialista ou diferencialista. A primeira nega as diferenças, buscando a homogeneização, a segunda é centrada no relativismo. Neste sentido, ambos processos "permitem a aplicação de critérios abstratos de normalização sempre baseados numa diferença que tem poder social para negar todas as demais ou para as declarar incomparáveis e, portanto, inassimiláveis" (SANTOS, 1999, p. 6). Assim:

No que diz respeito a desigualdade, a função consiste em manter a desigualdade dentro dos limites que não inviabilizem a integração subordinada. No que diz respeito à exclusão, a função consiste em distinguir, entre as diferentes formas de exclusão, aquelas que devem ser objeto de assimilação, ou pelo contrário, objecto de segregação, expulsão ou extermínio (SANTOS, 1999, p. 7)

Portanto, esclarece Santos (1999), o Estado tem que legitimar social e politicamente tal hierarquização, e o faz através de critérios tais como: "o louco", o “criminoso perigoso" e o "não perigoso"; "o bom e o mau imigrante"; "o povo indígena bárbaro e o aculturável", ou seja, busca-se identificar e reconhecer os "civilizáveis" e os “incivilizaveis” (SANTOS, 1999, p. 8).

Dessa forma, busca-se escalonar as diferenças e, então, identificar quais são "úteis" ao sistema e quais devem ser eliminadas por serem consideradas "perigosas". Assim, o mesmo modelo de controle social que é responsável pela produção da exclusão e desigualdade, procura mantê-las nos limites funcionais, tudo em nome da perpetuação do sistema (SANTOS, 1999, p. 8), dando-se novas roupagens as relações que, antes coloniais, hoje se dão na desigualdade entre países centrais e países periféricos. 
Portanto, as várias receitas de desenvolvimento que se encontram em uso pelos governos das mais variadas nações possuem o traço comum de manter determinados países, povos e setores dessas sociedades em dependência constante do mercado transnacional global e reféns dos interesses geopolíticos estratégicos das potências econômicas.

Sob o paradigma da modernidade, o conceito de desenvolvimento surge no pósguerra. Dito isto, é necessário que se tenha em mente que "desenvolvimento" implica em um resultado a ser alcançado, resultado este mediado por valores específicos.

Portanto, o conceito de desenvolvimento é um padrão permeado de normas e valores que se encontram intrinsecamente ligadas às relações de poder e de construção de uma hegemonia. Dessa forma, se faz necessário identificar quem estabelece o "dever ser" que constitui a espinha dorsal do ideário desenvolvimentista e como os dominados assumem, e ressignificam esses sentidos (LARREA, 2010, p. 17).

Desde el hegemón, todo aquello que no puede ser estructurado dentro de este dever ser pasa a ser desvalorizado, invisibilizado y desconocido. Se construye entonces, la idea del subdesarrollo, com una carga valorica que tiene que ver con ele atraso, lo no deseado, aquello que deve ser superado, desconociendo la riqueza de la diversidad identificada com los sectores subalternos, como eje constitutivo de nuestras sociedades. Desde la perspectiva de construccion de sentidos del campo del desarrollo y del subdesarrollo se construye un régimen de verdad que invisibiliza a las grandes mayorias de nuestra poblacion" (LARREA, 2010, p. 17)

Dessa forma, esse "regime de verdade" que é imposto aos países ditos "subdesenvolvidos", é racista e sexista, por invisibilizar povos, culturas, crenças, religiões, cosmovisões, lutas, histórias, e todo um passado próprio e único, com o claro intuito de estabelecer um padrão civilizatório próprio da modernidade.

\section{O bem-viver como alternativa aos modelos de desenvolvimento}

Na cosmovisão indígena andina, o "bem-viver”, acepção latina que se dá aos termos "sumak kawsay ou suma qamaña", se estende para lá de questões religiosas ou filosóficas. Diz respeito à criação e manutenção das diversas formas de vida que convivem nos mais variados ecossistemas do planeta Terra, por eles conhecido como "Pachamama".

Interessante ressaltar que o termo atualmente em voga "Pachamama", é uma junção do vocábulo "Pacha", originário da língua kolla-suyu, e que remete a ideia de "universo", "mundo", "pertencimento", e o vocábulo "Achachi” que, com o passar do tempo, 
e sob a influência cultural, política, religiosa, etc, dos conquistadores espanhóis, foi mutacionando-se para "Mama", termo latino para "mãe", "terra", remetendo a Nossa Senhora, representando clara influência do Catolicismo (PAREDES, 1920, p.38).

Assim, "Pachamama" é tudo aquilo que nos rodeia e do qual nossa própria matéria faz parte, significando a Natureza, o universo, a vida em toda a sua acepção.

No que diz respeito à forma como as pessoas se enxergam e veem o mundo nas sociedades indígenas equatorianas, por exemplo, Alberto Acosta (2008, p. 1) aponta a ausência de modelos de desenvolvimento. Isso quer dizer que para estes povos, não há sentido em se estabelecer um processo de "antes" e "depois" como sinônimo de evolução social, tal qual as acepções modernas de "desenvolvimento" e "subdesenvolvimento".

Neste sentido, Vasconcelos (2019) aponta que na cosmovisão indígena andina inexiste, como na cosmovisão moderno-ocidental, categorias de estágios ou formas de medir a qualidade da vida por meio de acréscimo ou decréscimo de bens materiais ou com base em padrões econômicos (VASCONCELOS, 2019, p. 94).

A cosmovisão do bem-viver presente nas Cartas Constitucionais do Equador e da Bolívia, não rejeita ou nega a importância dos avanços tecnológicos e desenvolvimentos científicos, e nem considera indesejável o acesso a bens e serviços advindos do modelo de sociedade moderna, mas sim busca o necessário equilíbrio entre os modos de ser, sentir, produzir, comercializar e consumir, próprios da modernidade, e a proteção integral ao espaço da vida.

O uso indiscriminado da Natureza pelo ser humano tem resultado em severas alterações no clima do planeta Terra. Tais consequências chamam a atenção para a urgência da necessidade de se mudar o rumo das intervenções antrópicas no ambiente.

O estilo de vida moderno, com seus excessos, tem dado claras mostras de que a forma e intensidade com que o ser humano vem intervindo nos sistemas regulatórios da vida são responsáveis pelo esgotamento dos solos, contaminação do ar, águas, desaparecimento de espécies, e de ecossistemas inteiros, dentre outros inúmeros danos ao sistema mantenedor da vida terrestre. 
Neste sentido, Acosta (2008) aponta que o crescimento material infinito poderia dar causa a um tipo de "suicídio coletivo", em consequência do aquecimento da atmosfera, da deterioração da camada de ozônio, pela perda de biodiversidade agrícola e silvestre, bem como pela contaminação de fontes de água potável, dentre tantas outras consequências fatais para a manutenção da vida humana e não humana no planeta (ACOSTA, 2008, p. 2), o que demonstra a necessidade da adoção de um modelo (ou modelos) de economia não destrutiva.

Vasconcelos (2019) aponta que o desenvolvimento econômico deve ser entendido como um meio, dentre tantos outros, para se atingir a satisfação plena das necessidades humanas e dos demais seres, com a necessária compatibilização das atividades econômicas com o respeito integral ao espaço da vida. Assim: "sua função social deve ser ecologizada, voltada para a promoção do bem-estar (não apenas econômico) das populações, tal qual o bem viver nas constituições equatoriana e boliviana" (VASCONCELOS, 2019, p. 109).

Acerca da economia tradicional do desenvolvimento, Amartya Sen (1985) afirma que as limitações que advêm deste modelo econômico não se dão necessariamente pela escolha dos meios para se alcançar o crescimento, mas sim pelo reconhecimento insuficiente de que o modelo de desenvolvimento econômico não é um fim em si mesmo mas sim um meio para se chegar a outros fins (SEN, 1985, p. 944). Inclusive, alerta o citado autor, os modelos que buscam o crescimento econômico nem mesmo poderiam ser entendidos como os meios mais eficientes quando de trata do campo das capacidades das gentes.

Dessa forma, os fins a serem atingidos pelas intervenções econômicas na Natureza devem mirar o pleno desenvolvimento das capacidades humanas, por um lado, e o menor impacto possível (resultante dessas intervenções) por outro. Em suma, deve-se buscar a satisfação das necessidades humanas sem que, para isso, se sacrifique o bem estar (ou mesmo a existência) de outras espécies.

Entretanto, o que se tem verificado é que o conceito tradicional de desenvolvimento econômico não se preocupa, ou preocupa-se muito pouco, com critérios que representam faces importantes das vidas das pessoas, como soberania alimentar (e não apenas segurança alimentar), a busca por realizações pessoais e comunitárias (para além das educacionais e profissionais), ou a busca pela melhora dos níveis de felicidade das pessoas. 
Sen (1985), ao falar das capacidades das pessoas, afirma que o processo de desenvolvimento econômico deve ser tratado como o processo de aumento da capacidade das pessoas, de forma que haja uma relação equilibrada entre os direitos e as possibilidades de materializá-los (SEN, 1985, p. 945).

Portanto, desenvolvimento não é um fim em si mesmo, mas um caminho possível para o progresso da humanidade. Entretanto, os modelos desenvolvimentistas que têm sido postos em prática têm revelado ser devastadores para as pessoas e a Natureza de todo o globo, por se fixarem em critérios economicistas e de produtividade, deixando o bem-estar físico, psicológico, social e natural sem qualquer atenção.

Ana Maria Larrea (2010) alerta que as inúmeras "receitas" para se alcançar o desenvolvimento, prometido pelos modelos de desenvolvimento econômico, têm levado a uma crise planetária sem precedentes, o que deixa claro que tal modelo é insustentável, apontando para a necessidade de se romper com a rota extrativista e devastadora para os países do Sul Global, bem como com as relações comerciais desiguais entre nações, e os padrões de consumo ilimitados que, caso persistam, levarão ao colapso dos sistemas de manutenção da vida do planeta ao não permitir sua capacidade de regeneração (LARREA, 2010, págs. 15/16).

Neste contexto, Vasconcelos (2019) alerta que:

\begin{abstract}
Aos padrões de consumo ilimitados da modernidade se poderia atribuir a pecha de esquizofrênicos, frente a sua aparente cegueira não biológica, mas igualmente patológica, para os resultados maléficos óbvios e reiterados de seus comportamentos. As sociedades modernas, no que pese as evoluções técnicas e informacionais que se sucederam, não parecem enxergar um mundo para além daquele desenhado segundo o modelo de Estado monista, antropocêntrico, hierárquico, instrumental-mecanicista, mercadocêntrico, e neocolonialista, autocentrando-se num modelo de sociedade identificada com a subjetivação de instituições ligadas ao Estado e ao mercado, ao passo que objetifica a Natureza e, em certa medida, os próprios seres humanos quando considerados "inferiores" sob a lógica do paradigma desenvolvimentista internacional. (VASCONCELOS, 2019, p. 20).
\end{abstract}

Assim, um dos caminhos possíveis, por via de importante mudança paradigmática, diz respeito ao questionamento ao próprio conceito de desenvolvimento e a busca de novas epistemologias baseadas nas cosmovisões dos povos ancestrais latinoamericanos, suas lutas emancipadoras e teorias críticas (LARREA, 2010, p. 15). 
Neste contexto, o novo constitucionalismo latino-americano surge como verdadeira alternativa ao conceito economicista de desenvolvimento, haja vista que sua lógica opera para além das amarras do paradigma antropocentrista-capitalista.

Assim, o "bem-viver", expressão máxima ao se descrever a forma de viver e se relacionar com a Natureza, e os demais seres, humanos ou não, apresenta-se como o ponto de partida para a organização da sociedade e do próprio Estado Nacional, ao quebrar a hierarquia existente entre seres humanos e não humanos, e pô-los em igualdade, reconhecendo e respeitando seus direitos e necessidades como sujeitos de direitos.

Como experiências materializadas no campo político-jurídico, podemos apontar as Constituições do Equador de 2008 e da Bolívia, de 2009. Neste sentido, destaca-se o artigo 71 da Carta Constitucional Equatoriana em que deixa claro que a Natureza não é vista como uma reserva econômica ou para a sobrevivência da espécie humana, mas como um ser vivo e reconhecida como sujeito de direitos:

Art. 71.- La naturaleza o Pacha Mama, donde se reproduce y realiza la vida, tiene derecho a que se respete integralmente su existencia y el mantenimiento y regeneración de sus ciclos vitales, estructura, funciones y procesos evolutivos.

Toda persona, comunidad, pueblo o nacionalidad podrá exigir a la autoridad pública el cumplimiento de los derechos de la naturaleza. Para aplicar e interpretar estos derechos se observaran los princípios establecidos en la Constitución, en lo que proceda (ECUADOR, 2008).

$\mathrm{O}$ artigo 72 da mesma Carta deixa mais claro que o respeito à Natureza se deve não aos prejuízos que o contrário possa causar aos seres humanos, mas sim em razão de sua dignidade.

Art. 72.- La naturaleza tiene derecho a la restauración. Esta restauración será independiente de la obligación que tienen el Estado y las personas naturales o jurídicas de Indemnizar a los individuos y colectivos que dependan de los sistemas naturales afectados (ECUADOR, 2008).

Quanto a Constituição Boliviana, fundamental destacar como princípios do Estado, o disposto em seu artigo $8^{\circ}$

Artículo 8 .

I - El estado asume y promueve como princípios etico-morales de la sociedad plural: ama qhilla, ama llulla, ama suwa (no seas flojo, no seas mentiroso no seas ladrón), suma qamaña (vivir bien), ñandereko (vida armoniosa), teko kawi (vida buena), ivi maraei (tierra sin mal) y qhapaj ñan (camino o vida noble)" (BOLÍVIA, 2009). 
Portanto, em ambas Constituições, resta claro que o status de sujeito de direitos é assegurado à Natureza, garantindo que qualquer indivíduo, ou coletividade, tenha legitimidade para litigar em juízo em nome da Natureza, pois que os direitos são dela e não dos humanos que em nome dela demandam (ZAFFARONI, 2001, p. 52).

O bem viver, representado nas citadas Constituições, busca o estabelecimento de formas não utilitaristas ou mercantilistas de relações entre seres humanos, demais seres vivos e a Natureza como um todo, mirando uma via alternativa e à imposta pelo paradigma da modernidade e seu modelo desenvolvimentista, servindo de clara demonstração de que é possível (e desejável) trilhas por caminhos verdadeiramente sustentáveis.

\section{Conclusão}

$\mathrm{O}$ atual modelo de desenvolvimento que vem sendo (im)posto em prática no mundo todo tem levado ao esgotamento da Natureza e a extinção de inúmeros seres vivos. No centro deste "estilo de vida" se encontra o paradigma da modernidade, que impõe modelos de produção, uso, acumulação e consumo

O carro-chefe da modernidade se traduz pelo modelo sócio-econômico desenvolvimentista, que parte da perspectiva de que o Continente Europeu (ou mais precisamente os países centrais) é o ápice de uma suposta evolução da sociedade humana, e que, neste caminho evolutivo, os demais países e povos do Globo estão ainda em “desenvolvimento" (ZAFFARONI, 2010, p. 126).

Dessa forma, se impõe aos países “em desenvolvimento", que percorram uma via ditada pelos países desenvolvidos, em que os primeiros devem se submeter a uma série de regras para que se "desenvolvam".

Diante deste quadro, a quebra paradigmática do antropocentrismo para o biocentrismo representa a inversão da lógica utilitarista que enxerga e trata o meio ambiente como mero recurso ao bem-estar (que é diferente de bem-viver) do ser humano, e que trata os demais seres como inferiores, própria das sociedades capitalistas modernas e de seu modelo desenvolvimentista.

Aponta ZAFFARONI (2011) que: 
No se trata tampoco de limitar esos derechos a los animales, sino de reconocerlos a las plantas y a los seres microscópicos en tanto formamos parte de un continuo de vida, e incluso a la materia aparentemente inerte, que no estan inerte como parece (ZAFFARONI, 2011, p. 36).

Diante disso, o bem-viver, forma de se relacionar com os seres e com a própria Natureza, constitucionalizado através do novo constitucionalismo latino-americano, apresenta-se como importante instrumento jurídico contra o eurocentrismo e as práticas neocoloniais típicas da relação "centro/periferia" e de seu modelo desenvolvimentista, representando resposta plural, participativa e democrática (MAGALHÃES, 2008, p. 203).

Neste sentido, afirma Agustin Grijalva Jimenez (2008) que:

El constitucionalismo plurinacional debe ser un nuevo tipo de constitucionalismo basado em relaciones interculturales igualitarias que redefinan y reinterpreten los derechos constitucionales y reestruturen la institucionalidad proveniente del Estado Nacional. El Estado Plurinacional no es, o no debe reducirse a una Constitucion que incluye un reconocimiento puramente culturalista (...), sino un sistema de foros de deliberacion autenticamente democrática" (GRIJALVA, 2008, p. 50-51).

Aliada a esta proposta paradigmática, se encontra a cosmovisão do biocentrismo que identifica na personificação da Pachamama, representada pela Natureza, um ser vivo e sujeito de direitos, o que faz necessário a revisão da forma como o ser humano se relaciona com o ambiente natural que o rodeia e com os demais seres vivos.

Dessa forma, o sumak kawsay/suma qamaña, ou "bem viver", passa a ser o paradigma norteador da relação humano/natureza. Neste sentido:

La naturaleza puede ser usada para vivir, pero no suntuariamente, es decir, para lo que no es necesario. La infinita creacion de necesidades artificiales que sostienen el crecimiento ilimitado del consumo estaria limitada por el criterio del sumak kawsay" (ZAFFARONI, 2010).

Portanto, as recentes experiências constitucionais Equatoriana e Boliviana têm demonstrado a possibilidade real de caminhos que levem a alternativas aos modelos de desenvolvimento até então postos em prática, e não apenas variações de tais modelos.

Desta forma, estar-se-ia trilhando a via do "bem viver", inserindo-se na macrovisão holística acerca da interação entre o ser humano, demais animais, e a Natureza, assimilando a lógica da interculturalidade entre seres, povos, etnias, culturas, etc, buscando uma fusão epistemológica entre os saberes tradicionais e a ciência clássica, com vistas a se 
atingir o bem comum (SOUSA SANTOS, 1999, pg. 23-71) e a superação de um modelo voltado para a mercantilização do solo, da água, dos seres, das gentes, em suma, da própria vida.

\section{REFERÊNCIAS}

ACOSTA, Alberto. El Buen Vivir, una oportunidad por construir. Ecuador debate, v. 75, n. 1, p. 33-48, 2008. Disponível em: http://www.otrodesarrollo.com/buenvivir/Ecuador_Debate_dic.2008.pdf>. Acesso em: 27 de julho de 2017.

BOLÍVIA. Constitucion Politica del Estado. La Paz: Congreso Nacional, 2009. Disponível em: <https://www.vicepresidencia.gob.bo/IMG/pdf/ncpe_cepd.pdf>. Acesso em: 25 de julho de 2017.

ECUADOR. Constitucion Política de la República del Ecuador. Riobamba: Congreso Nacional, 2008. Disponível em: http://www.asambleanacional.gov.ec/documentos/constitucion_de_bolsillo.pdf $>$. Acesso em: 29 de julho de 2017.

GRIJALVA, Agustin, El Estado Plutinacional e Intercultural em la Constitucion Ecuatoriana de 2008. In Ecuador Debate 75. Quito - Ecuador, Deciembre de 2008, p. 49-62. Disponível em: < http://repositorio.flacsoandes.edu.ec/bitstream/10469/4170/1/RFLACSO-ED75-04Grijalva.pdf>. Acesso em: 23 de julho de 2017.

LARREA, Ana María. La disputa de sentidos por el buen vivir como proceso contrahegemónico. Los nuevos retos de América Latina. Socialismo y sumak kawsay”. SENPLADES, Quito, p. 15-27, 2010. Disponível em: < http://latinoamericana.org/2012/info/docs/SocialismoYSumakKawsay.pdf\#page=15>. Acesso em: 23 de julho de 2017.

MAGALHÃES, José Luiz Quadros. Plurinacionalidade e Cosmopolitismo: a diversidade cultural das cidades e diversidade comportamental nas metrópoles. In Revista de Direitos e Garantias Fundamentais da Faculdade de Direito de Vitória, nº 7, p. 203 a 216, jan/jun de 2010.

Disponível em: 
https://www.direito.ufmg.br/revista/index.php/revista/article/viewFile/83/79>. Acesso em: 21 de julho de 2017.

QUIJANO, Aníbal. Colonialidad del poder, eurocentrismo y América Latina. 2000.

Disponível em: <https://s3.amazonaws.com/academia.edu.documents/45925192/AnibalQuijano_Colonialidad_del_poder_eurocentrismo....pdf?AWSAccessKeyId=AKIAIWOW YYGZ2Y53UL3A\&Expires=1502481809\&Signature=\%2Bf3spyMI7uO0Mig1t $1 \mathrm{~g} 8 \mathrm{c} 3 \mathrm{oHU}$ 7c\%3D\&response-contentdisposition=inline \%3B\%20filename\%3DColonialidad_del_poder_eurocentrismo_y_A.pdf >. Acesso em: 21 de julho de 2017.

PAREDES, M. Rigoberto, Mitos, superticiones y supervivências populares de Bolivia. LaPaz: Arno Hermanos, 1920.

SANTOS, Boaventura de Sousa. A construção multicultural da igualdade e da diferença. 1999. Disponível em: https://estudogeral.sib.uc.pt/bitstream/10316/11020/1/A\%20Constru\%C3\%A7\%C3\%A3o \%20Multicultural\%20da\%20Igualdade\%20e\%20da\%20Diferen\%C3\%A7a.pdf>. Acesso em: 21 de julho de 2017.

SEN, Amartya; "Cuál es el camino del desarrollo". In Comercio Exterior, volume 35, № 10, México, outubro de 1985. Disponivel em: < http://revistas.bancomext.gob.mx/rce/magazines/299/2/RCE2.pdf >. Acesso em: 5 de agosto de 2017.

VASCONCELOS, Adriano Ermerson Oliveira. O estudo de impacto ambiental nas atividades agrárias sucroalcooleiras no estado de Goiás: Uma análise em perspectiva biocêntrica do bem viver. 2019. Dissertação (Mestrado em Direito Agrário) - Faculdade de Direito, Universidade Federal de Goiás, Goiânia. Disponível em:<https://repositorio.bc.ufg.br/tede/bitstream/tede/9362/5/Disserta\%C3\%A7\%C3\%A3o \%20-\%20Adriano\%20Ermerson\%200liveira\%20Vasconcelos\%20-\%202019.pdf>. Acesso em 18 de maio de 2019.

ZAFFARONI, Euggenio Raúl. La Pachamama y el humano. Buenos Aires: Colihue, 2011. Disponível em: http://therightsofnature.org/wp- 
content/uploads/pdfs/Espanol/Zaffaroni_Pachamama_Humano_s.f..pdf>.

Acesso

em

08/08/2017. 